Article

\title{
Investigation of the Impact of Endodontic Therapy on Survival among Dialysis Patients in Taiwan: A Nationwide Population-Based Cohort Study
}

\author{
Chih-Chien Chiu ${ }^{1,2}$, Ya-Chieh Chang ${ }^{3,4}$, Ren-Yeong Huang ${ }^{5}$, Jenq-Shyong Chan ${ }^{3,4}$, Chi-Hsiang Chung ${ }^{6}(\mathbb{B}$, \\ Wu-Chien Chien ${ }^{6,7,+}+\mathbb{D}$, Yung-Hsi Kao ${ }^{8,+}$ and Po-Jen Hsiao ${ }^{3,4,8, *,+}+\mathbb{C}$
}

Citation: Chiu, C.-C.; Chang, Y.-C.; Huang, R.-Y.; Chan, J.-S.; Chung, C.-H.; Chien, W.-C.; Kao, Y.-H.; Hsiao, P.-J. Investigation of the Impact of Endodontic Therapy on Survival among Dialysis Patients in Taiwan: A Nationwide Population-Based Cohort Study. Int. J. Environ. Res. Public Health 2021, 18, 326. https://doi.org/ 10.3390/ijerph18010326

Received: 5 December 2020 Accepted: 30 December 2020 Published: 5 January 2021

Publisher's Note: MDPI stays neutral with regard to jurisdictional clai$\mathrm{ms}$ in published maps and institutional affiliations.

Copyright: (C) 2021 by the authors. Licensee MDPI, Basel, Switzerland. This article is an open access article distributed under the terms and conditions of the Creative Commons Attribution (CC BY) license (https:// creativecommons.org/licenses/by/ $4.0 /)$
1 Division of Infectious Disease, Department of Internal Medicine, Taoyuan Armed Forces General Hospital, Taoyuan City 325, Taiwan; calebchiu.tw@gmail.com

2 Division of Infectious Disease and Tropical Medicine, Department of Internal Medicine, Tri-Service General Hospital, National Defense Medical Center, Taipei 114, Taiwan

3 Division of Nephrology, Department of Internal Medicine, Taoyuan Armed Forces General Hospital, Taoyuan City 325, Taiwan; ajie1124@gmail.com (Y.-C.C.); jschan0908@yahoo.com.tw (J.-S.C.)

4 Division of Nephrology, Department of Internal Medicine, Tri-Service General Hospital, National Defense Medical Center, Taipei 114, Taiwan

5 Department of Periodontology, School of Dentistry, Tri-Service General Hospital, National Defense Medical Center, Taipei 114, Taiwan; ndmcandy@mail.ndmctsgh.edu.tw

6 School of Public Health, National Defense Medical Center, Taipei 114, Taiwan; g694810042@gmail.com (C.-H.C.); chienwu@ndmctsgh.edu.tw (W.-C.C.)

7 Department of Medical Research, Tri-Service General Hospital, Taipei 114, Taiwan

8 Department of Life Sciences, National Central University, Taoyuan City 320, Taiwan; ykao@cc.ncu.edu.tw

* Correspondence: a2005a660820@yahoo.com.tw; Tel.: +886-3-479-9595; Fax: +886-3-480-1625

+ These authors contributed equally to this work.

Abstract: Objectives Dental problems occur widely in patients with chronic kidney disease (CKD) and may increase comorbidities. Root canal therapy (RCT) is a common procedure for advanced decayed caries with pulp inflammation and root canals. However, end-stage renal disease (ESRD) patients are considered to have a higher risk of potentially life-threatening infections after treatment and might fail to receive satisfactory dental care such as RCT. We investigated whether appropriate intervention for dental problems had a potential impact among dialysis patients. Design Men and women who began maintenance dialysis (hemodialysis or peritoneal dialysis) between January 1 , 2000, and December 31, 2015, in Taiwan (total 12,454 patients) were enrolled in this study. Participants were followed up from the first reported dialysis date to the date of death or end of dialysis by December 31, 2015. Setting Data collection was conducted in Taiwan. Results A total of 2633 and 9821 patients were classified into the RCT and non-RCT groups, respectively. From the data of Taiwan's National Health Insurance, a total of 5,092,734 teeth received RCT from 2000 to 2015. Then, a total of 12,454 patients were followed within the 16 years, and 4030 patients passed away. The results showed that members of the non-RCT group (34.93\%) had a higher mortality rate than those of the RCT group $(22.79 \% ; p=0.001)$. The multivariate-adjusted hazard ratio for the risk of death was 0.69 (RCT vs. non-RCT; $p=0.001$ ). Conclusions This study suggested that patients who had received RCT had a relatively lower risk of death among dialysis patients. Infectious diseases had a significant role in mortality among dialysis patients with non-RCT. Appropriate interventions for dental problems may increase survival among dialysis patients. Abbreviations: $\mathrm{CKD}=$ chronic kidney disease, $\mathrm{ESRD}=$ end-stage renal disease, $\mathrm{RCT}=$ root canal therapy.

Keywords: root canal therapy; dialysis; end-stage renal disease; survival

\section{Introduction}

The marked disparities in the incidence and prevalence of treated end-stage renal disease (ESRD) worldwide are well known. Through the United States Renal Data System 
2019 Annual Data Report, as seen over the past decade, Taiwan still reported the highest treated ESRD incidence worldwide, with a rate of 504 patients per million general population (PMP). Concurrently, the highest treated ESRD prevalence has also been reported in Taiwan to be 3480 PMP [1]. It is recognized that diabetic nephropathy is the leading cause of ESRD in both developed and developing countries. A case-control study in Taiwan performed by Tsai et al. [2] indicated that a history of hypertension, diabetes, low socioeconomic status, and regular use of folk remedies or over-the-counter Chinese herbs were crucial risk factors for ESRD. Progressive chronic kidney disease (CKD) can cause several complications in other parts of the body with a higher prevalence and intensity as kidney function decreases, including cardiovascular events, anemia, mineral and bone disorders, fluid retention, metabolic acidosis, electrolyte disturbances, and infectious diseases [3]. The leading cause of death in both dialysis and transplanted patients is cardiovascular disease, with the ratio reported to be 10- to 20-fold higher than that observed in populations with normal kidney function. Nevertheless, there are still many patients who die from non-cardiovascular causes, with infectious diseases and malignancies being the most common $[1,4-6]$.

However, while clinicians focus on the complications described above, oral health and dental problems are easily neglected. Otherwise, a poor oral condition and its intricate consequences are closely associated with the incidence and progression of CKD. Dental caries and periodontal inflammation affect several different populations, such as pregnant women [7]. Previous studies have also demonstrated excessive rates of oral pathology in CKD patients with one or more oral complications, such as periodontitis, xerostomia, mucositis, and enamel hypoplasia [8-11]. These symptoms may worsen with declining renal function, resulting in systemic inflammation and malnutrition. CKD has been proven to be a potential mortality risk because of its accelerating impact on cardiovascular disease. Although more adults with CKD suffer from oral disorders than the general public, they may instead receive fewer dental services. A multinational cohort study by Palmer et al. [12] indicated that poor oral health was linked to early death in dialysis patients, whereas preventive dental health practice was predominant in longer survival. Endodontic therapy, also known as root canal therapy (RCT), is indicated when the pulp or soft tissue inside a tooth is damaged by bacterial infection [13]. RCT is a complex therapeutic procedure involving the removal of damaged pulp, cleaning of the infection, and filling the emptied space, and it is classified as a high-cost medical treatment in Taiwan. However, the low socioeconomic status followed by the difficulties in starting a job among hemodialized patients result in the neglect of oral hygiene [14]. Currently available evidence has demonstrated that oral infection may be the site of origin for the dissemination of pathogenic organisms, as their products enter the bloodstream to travel to distant body sites and thus affect the course and pathogenesis of cardiovascular disease, bacterial pneumonia, diabetes mellitus, and low birth weight [15]. Furthermore, hemodialysis and reductions in oral fluid intake can decrease the salivary flow rate and result in changes in oral mucous membranes, leading to xerostomia and increased calculus formation, which add to the risk for microbial infection [16].

We will present an observational retrospective cohort study aimed to investigate the potential effect of receiving appropriate root canal therapy on survival probability in dialysis patients.

\section{Materials and Methods}

\subsection{Database}

Taiwan instituted compulsory universal National Health Insurance (NHI) in 1995, and the health insurance coverage rate currently exceeds $99 \%$ of residents. The NHI database is one of the largest and most complete population-based datasets in the world, collecting information from all insured persons, including detailed health services, such as medications, disease diagnoses, examinations, and treatments. The accuracy and validity of the diagnoses have been well demonstrated [17-21]. This study used outpatient and 
inpatient data, as well as demographic data. Approval for this study was provided by the Institutional Review Board of the Tri-Service General Hospital (TSGH), National Defense Medical Center (Approval No: TSGHIRB-B-109-37).

\subsection{Definition of Dialysis Patients}

This retrospective cohort study enrolled patients who began maintenance dialysis (hemodialysis or peritoneal dialysis) between 1 January 2000 and 31 December 2015. Patients on dialysis were defined by their dialysis codes based on outpatient data. In the case of hemodialysis codes, 58001C, 58014C, 58018C, 58019C, 58020C, 58021C, 58022C, $58023 \mathrm{C}, 58024 \mathrm{C}, 58025 \mathrm{C}, 58026 \mathrm{C}, 58027 \mathrm{C}, 58029 \mathrm{C}, 58030 \mathrm{~B}$, and $69006 \mathrm{C}$ were all sufficient for inclusion. For those with peritoneal dialysis codes, 58001CA, 58002C, 58009A, 58009B, 58010A, 58010B, 58011A, 58011AB, 58011B, 58011C, 58012A, 58012B, 58017B, 58017C, and $58028 \mathrm{C}$ were all acceptable. Patients who were younger than 20 years old were excluded. Patients had to have undergone hemodialysis or peritoneal dialysis for at least 3 months.

\subsection{Definition of Dialysis Patients with RCT}

The procedures of RCT included open chamber, root canal cleaning, and enlargement by either rotary or hand instruments, copious irrigation, and obturation by Gutta-Percha. The procedures and quality followed the therapeutic guidelines and were checked and verified by board-certified endodontist. In this study, we used outpatient data to identify maintenance dialysis patients according to their RCT codes and to classify them into two groups: non-RCT (no codes) and RCT (codes 90001C, 90002C, 90003C, 90004C, or 90015C). RCT was performed after the initiation of dialysis. Subjects with RCT were identified when the first tooth received RCT if multiple teeth were treated after beginning dialysis.

\subsection{Primary Outcome}

The primary outcome was all-cause mortality during the period of 1 January 2000 to 31 December 2015.

\subsection{Definition of Death}

Death was defined as withdrawal of the patient from the NHI program.

\subsection{Definition of Other Variables}

Demographic data included sex, age at the initiation of dialysis, and monthly income. There are two types of dialysis: hemodialysis (HD) and peritoneal dialysis (PD). Conditions diagnosed before the start date of dialysis, namely, diabetes mellitus (ICD-9 codes 250.x), hypertension (ICD-9 code 362.11, 401.x-405.x, 437.2), gout (ICD-9 codes 274.0-274.9), congestive heart failure (ICD-9 code 428.0-428.9, 398.91), coronary artery disease (ICD-9 codes $410 . x x-414 . x x)$, cerebrovascular accidents (ICD-9 codes 430-438.xx), peripheral artery disease (ICD-9 code 440.0-440.9, 38.13-38.18, 39.22-39.26, 39.28), chronic lung disease (ICD9 codes 490-496.x, 500-505.x, 506.4x), chronic liver disease (ICD-9 code 571.x), malignancy (ICD-9 codes 140-208), and retinopathy (ICD-9 code 362.x) were identified as comorbidities.

\subsection{Statistical Analysis}

SAS software (SAS System for Windows, version 9.2; SAS Institute, Cary, NC, USA) was used to perform all statistical analyses in this study. Descriptive statistics were used to analyze the demographic data and the distribution of each variable among the study population. Continuous variables were described as the mean \pm statistical difference (SD) and were compared using independent $t$-test analysis of variance. Categorical variables were described as proportions and compared using the chi-square test. The chi-square test was used to compare each variable in the groups of patients with and without RCT. The cumulative proportion of patients with and without RCT was calculated using the Kaplan-Meier method, and the difference in survival was determined by the log-rank test. Univariate and multivariate analyses were performed with the Cox proportional hazards 
model. To adjust for potential confounding factors in the relationship between comorbidity, multivariate analysis was used. A $p$-value of $<0.05$ was considered statistically significant.

\section{Results}

The records in the NHI databank indicated a total of 14,471 patients on dialysis from 2000 to 2015, 12,454 of whom received maintenance dialysis. A total of 5,092,734 teeth in dialysis patients received RCT between 2000 and 2015. We combined the dialysis data with the RCT data and selected the first tooth per patient if multiple teeth received treatment after the start of dialysis. Among the 12,454 patients with maintenance dialysis, 2633 patients received RCT in the follow-up period, whereas 4030 patients died (Figure 1).

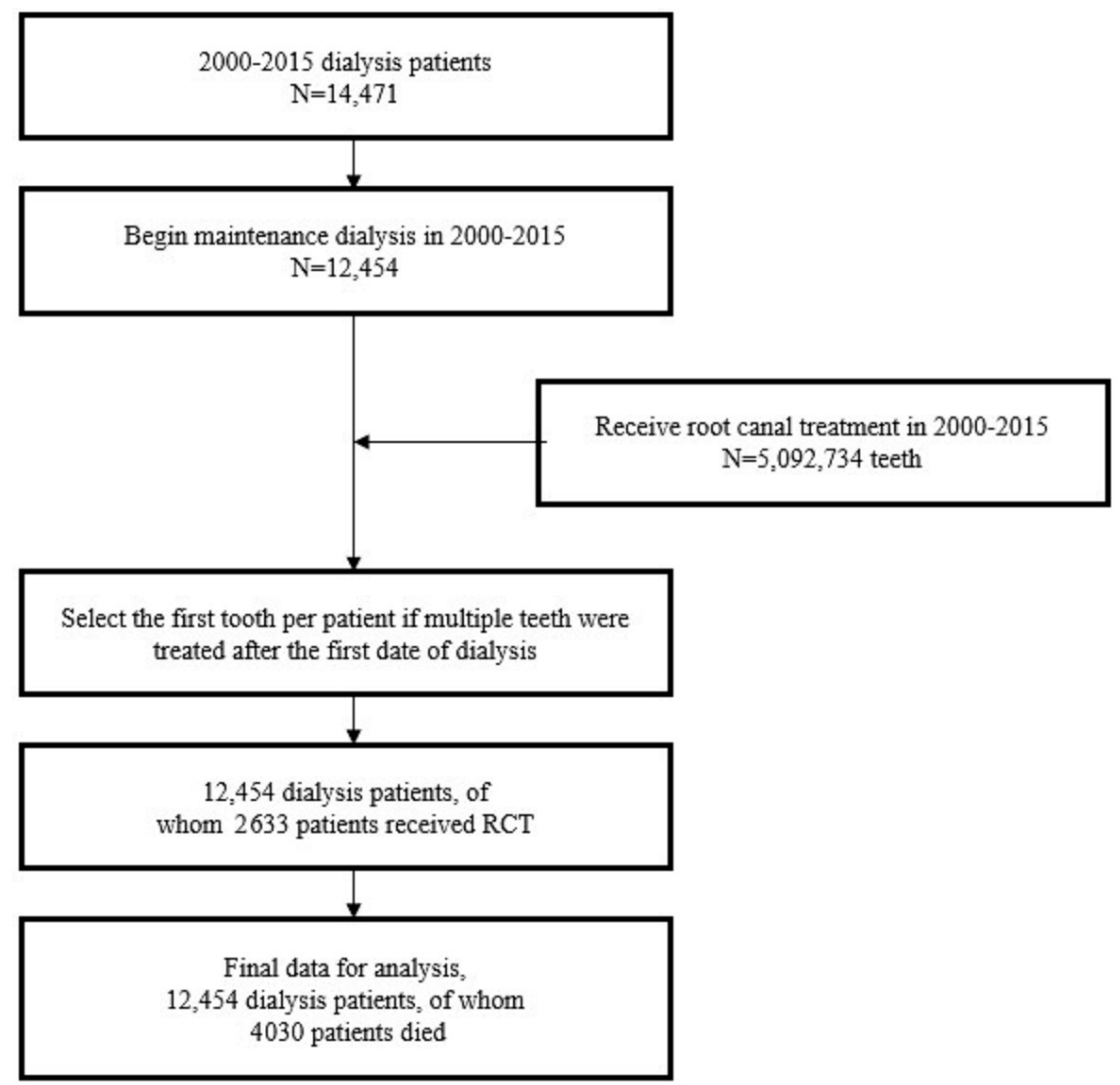

Figure 1. The retrospective cohort study flow diagram.

\subsection{Clinical Characteristics}

Table 1 presents the distribution of demographic characteristics, comorbidities, and deaths for the non-RCT and RCT groups. The mean patient age was 57.02 years $( \pm 14.75)$ in members of the non-RCT group and 54.93 years $( \pm 13.84)$ in members of the RCT group $(p<0.001)$. In addition, more women were observed to have undergone RCT $(p<0.001)$ than men. Compared with patients in the RCT group, patients in the non-RCT group were more likely to have diabetes mellitus ( $32.84 \%$ vs. $22.18 \%$; $p<0.001)$, hypertension $(51.18 \%$ vs. $39.95 \% ; p<0.001)$, hyperlipidemia $(15.71 \%$ vs. $11.28 \% ; p<0.001)$, congestive heart failure $(5.69 \%$ vs. $4.75 \% ; p<0.001)$, coronary artery disease $(12.20 \%$ vs. $8.89 \%$; $p<0.001)$, cerebrovascular accident ( $9.73 \%$ vs. $7.48 \% ; p<0.001)$, and retinopathy $(16.70 \%$ vs. $11.70 \%$; $p<0.001)$. Furthermore, members of the non-RCT group displayed higher mortality rates than those of the RCT group ( $34.93 \%$ vs. $22.79 \% ; p=0.001$ ). In contrast, malignancy was less common among the patients in the non-RCT group than in the RCT group $(3.48 \%$ vs. $5.28 \% ; p<0.001)$.

Table 2 presents the distribution of demographic characteristics and comorbidities associated with death status. The mean ages at death during the 16-year follow-up period were $65.06( \pm 12.19)$ and 52.52 years $( \pm 13.88)$ for patients in the death and non-death 
groups, respectively $(p<0.001)$. Except for patients with peripheral arterial disease, the dialysis group had higher mortality rates for patients with any of the other comorbidities $(p<0.001)$.

Table 1. Demographic characteristics of dialysis patients with and without root canal therapy (RCT) in the years 2000-2015 $(n=12,454)$.

\begin{tabular}{|c|c|c|c|c|c|}
\hline \multirow{3}{*}{ Variables } & \multirow{2}{*}{\multicolumn{2}{|c|}{$\begin{array}{l}\text { Non-RCT } \\
(n=9821)\end{array}$}} & \multirow{2}{*}{\multicolumn{2}{|c|}{$\begin{array}{c}\text { RCT } \\
(n=2633)\end{array}$}} & \multirow{3}{*}{$p$} \\
\hline & & & & & \\
\hline & $\mathbf{n}$ & $\%$ & $\mathbf{n}$ & $\%$ & \\
\hline Age (mean, sd) ${ }^{a}$ & \multirow{2}{*}{\multicolumn{2}{|c|}{$57.02 \pm 14.75$}} & \multirow{2}{*}{\multicolumn{2}{|c|}{$54.93 \pm 13.84$}} & \multirow{4}{*}{$\begin{array}{l}<0.001 * \\
<0.001 \text { * }\end{array}$} \\
\hline Sex & & & & & \\
\hline Female & 5009 & 51.00 & 1493 & 56.70 & \\
\hline Male & 4812 & 49.00 & 1140 & 43.30 & \\
\hline Monthly income & & & & & \multirow[t]{5}{*}{$0.001 *$} \\
\hline No income & 1942 & 19.77 & 473 & 17.96 & \\
\hline NT\$1-15,840 & 1528 & 15.56 & 352 & 13.37 & \\
\hline NT\$15,841-25,000 & 4917 & 50.07 & 1375 & 52.22 & \\
\hline$\geq \mathrm{NT} \$ 25,001$ & 1434 & 14.60 & 433 & 16.45 & \\
\hline Dialysis type & & & & & \multirow[t]{3}{*}{0.022 * } \\
\hline HD & 8920 & 90.83 & 2352 & 89.33 & \\
\hline PD & 901 & 9.17 & 281 & 10.67 & \\
\hline \multicolumn{6}{|l|}{ Comorbidity } \\
\hline Diabetes mellitus & 3225 & 32.84 & 584 & 22.18 & $<0.001 *$ \\
\hline Hypertension & 5026 & 51.18 & 1052 & 39.95 & $<0.001$ * \\
\hline Hyperlipidemia & 1543 & 15.71 & 297 & 11.28 & $<0.001$ * \\
\hline Gout & 1121 & 11.41 & 281 & 10.67 & 0.285 \\
\hline Congestive heart failure & 559 & 5.69 & 125 & 4.75 & $<0.001$ * \\
\hline Coronary artery disease & 1198 & 12.20 & 234 & 8.89 & $<0.001 *$ \\
\hline Cerebrovascular accident & 956 & 9.73 & 197 & 7.48 & $<0.001 *$ \\
\hline Peripheral arterial disease & 101 & 1.03 & 20 & 0.76 & 0.263 \\
\hline Chronic lung disease & 974 & 9.92 & 235 & 8.93 & 0.127 \\
\hline Chronic liver disease & 782 & 7.96 & 192 & 7.29 & 0.255 \\
\hline Malignancy & 342 & 3.48 & 139 & 5.28 & $<0.001 *$ \\
\hline Retinopathy & 1640 & 16.70 & 308 & 11.70 & $<0.001 *$ \\
\hline Death & 3430 & 34.93 & 600 & 22.79 & $0.001 *$ \\
\hline Follow-up years (means, sd) ${ }^{a}$ & \multicolumn{2}{|c|}{$9.89 \pm 2.93$} & \multicolumn{2}{|c|}{$9.71 \pm 2.89$} & 0.001 * \\
\hline
\end{tabular}

* $p<0.05 ;{ }^{a}$ Independent-Samples t Test. HD = Hemodialysis; PD = Peritoneal dialysis.

Table 2. Demographic characteristics of dialysis patients who died during 16 years.

\begin{tabular}{|c|c|c|c|c|c|}
\hline \multirow{3}{*}{ Variables } & \multirow{2}{*}{\multicolumn{2}{|c|}{$\begin{array}{c}\text { Death } \\
(n=4030)\end{array}$}} & \multirow{2}{*}{\multicolumn{2}{|c|}{$\begin{array}{c}\text { Non-Death } \\
(\mathrm{n}=8424)\end{array}$}} & \multirow{3}{*}{$p$} \\
\hline & & & & & \\
\hline & $\mathbf{n}$ & $\%$ & $\mathbf{n}$ & $\%$ & \\
\hline Age (means, sd) ${ }^{a}$ & \multirow{2}{*}{\multicolumn{2}{|c|}{$65.06 \pm 12.19$}} & \multirow{2}{*}{\multicolumn{2}{|c|}{$52.52 \pm 13.88$}} & \multirow{4}{*}{$\begin{array}{l}<0.001 * \\
<0.001\end{array}$} \\
\hline Sex & & & & & \\
\hline Female & 1990 & 49.38 & 4512 & 53.56 & \\
\hline Male & 2,040 & 50.62 & 3912 & 46.44 & \\
\hline Monthly income & & & & & \multirow[t]{5}{*}{$<0.001 *$} \\
\hline No income & 944 & 23.42 & 1471 & 17.46 & \\
\hline NT\$1-15,840 & 613 & 15.21 & 1267 & 15.04 & \\
\hline NT\$15,841-25,000 & 2025 & 50.25 & 4267 & 50.65 & \\
\hline$\geq \mathrm{NT} \$ 25,001$ & 448 & 11.12 & 1419 & 16.84 & \\
\hline Dialysis type & & & & & \multirow[t]{3}{*}{$<0.001 *$} \\
\hline HD & 3703 & 91.89 & 7569 & 89.85 & \\
\hline PD & 327 & 8.11 & 855 & 10.15 & \\
\hline \multicolumn{6}{|l|}{ Comorbidity } \\
\hline Diabetes mellitus & 2066 & 51.27 & 1743 & 20.69 & $<0.001 *$ \\
\hline Hypertension & 2569 & 63.75 & 3509 & 41.65 & $<0.001 *$ \\
\hline Hyperlipidemia & 877 & 21.76 & 963 & 11.43 & $<0.001 *$ \\
\hline Gout & 601 & 14.91 & 801 & 9.51 & $<0.001 *$ \\
\hline Congestive heart failure & 432 & 10.72 & 252 & 2.99 & $<0.001 *$ \\
\hline Coronary artery disease & 871 & 21.61 & 561 & 6.66 & $<0.001 *$ \\
\hline Cerebrovascular accident & 709 & 17.59 & 444 & 5.27 & $<0.001^{*}$ \\
\hline Peripheral arterial disease & 44 & 1.09 & 77 & 0.91 & 0.379 \\
\hline Chronic lung disease & 692 & 17.17 & 517 & 6.14 & $<0.001 *$ \\
\hline Chronic liver disease & 478 & 11.86 & 496 & 5.89 & $<0.001$ * \\
\hline Malignancy & 245 & 6.08 & 236 & 2.80 & $<0.001 *$ \\
\hline Retinopathy & 1009 & 25.04 & 939 & 11.15 & $<0.001$ * \\
\hline
\end{tabular}




\subsection{Predictors of Survival Rates}

We used the Kaplan-Meier method to analyze survival rates for those who did or did not receive $\mathrm{RCT}$, as determined by the log-rank test. Those in the non-RCT group demonstrated a lower survival rate than those in the RCT group $(\log$-rank $p<0.001)$ (Figure 2). Subsequently, univariate and multivariate Cox proportional models were used to adjust the mortality rates in both groups of subjects (Table 3). A significant association was observed between an increased risk of death with older age, diabetes mellitus, coronary artery disease, cerebrovascular accident, chronic lung disease, chronic liver disease, malignancy, and non-RCT status (all $p<0.05$ ). Demographic variables (age, monthly income, dialysis type) and comorbidities, including diabetes mellitus, hypertension, hyperlipidemia, gout, congestive heart failure, coronary artery disease, cerebrovascular accidents, peripheral arterial disease, chronic lung disease, chronic liver disease, malignancy, and retinopathy, were entered into the regression analysis. The multivariate-adjusted hazard ratio for the risk of death was 0.69 (RCT vs. non-RCT; $p=0.001$ ) (Table 4 ). Taken together, the results suggest that dialysis patients who undergo RCT may have a lower risk of death than dialysis patients who do not undergo RCT.

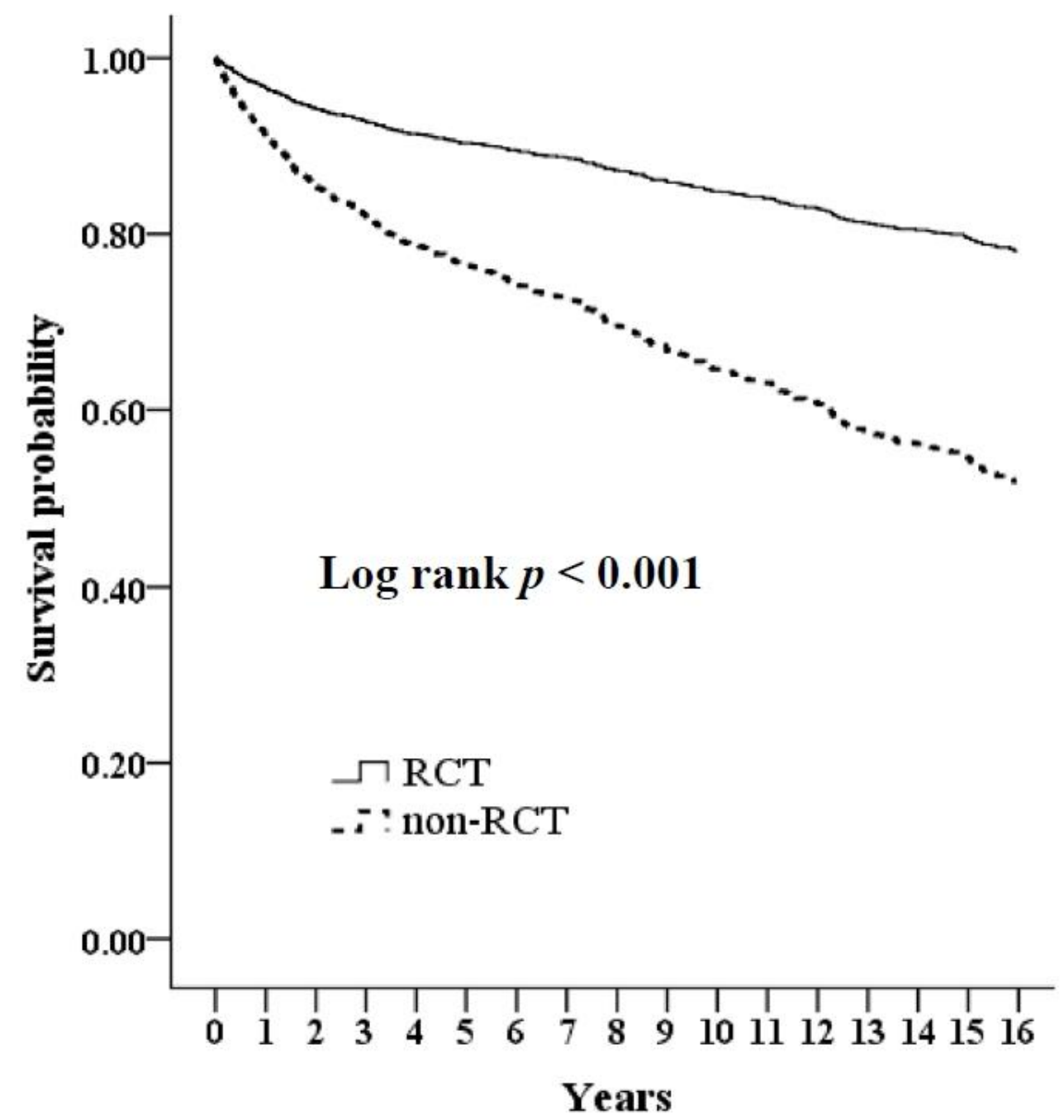

Figure 2. Cumulative survival in dialysis patients with RCT compared to without RCT. The cohort study was followed up for 16 years. 
Table 3. Hazard ratios of risk of death among dialysis patients with RCT and without RCT.

\begin{tabular}{|c|c|c|c|c|c|c|}
\hline \multirow{2}{*}{ Variables } & \multicolumn{3}{|c|}{ Univariate } & \multicolumn{3}{|c|}{ Multivariate } \\
\hline & HR & $95 \% \mathrm{CI}$ & $p$ & HR & $95 \% \mathrm{CI}$ & $p$ \\
\hline Age & 1.09 & $1.06-1.10$ & $<0.001 *$ & 1.07 & $1.05-1.09$ & $<0.001 *$ \\
\hline Men (Women $\S$ ) & 1.15 & $0.97-1.34$ & 0.082 & 1.11 & $0.91-1.29$ & 0.273 \\
\hline \multicolumn{7}{|l|}{$\begin{array}{l}\text { Monthly income } \\
\text { (No income }{ }^{\S} \text { ) }\end{array}$} \\
\hline NT\$1-15,840 & 0.80 & $0.61-1.04$ & 0.062 & 0.99 & $0.86-1.31$ & 0.704 \\
\hline NT\$15,841-25,000 & 0.79 & $0.62-0.93$ & $0.009 *$ & 0.84 & $0.78-1.24$ & 0.677 \\
\hline$\geq \mathrm{NT} \$ 25,001$ & 0.56 & $0.40-0.71$ & $<0.001 *$ & 0.79 & $0.60-1.03$ & 0.125 \\
\hline $\mathrm{HD}\left(\mathrm{PD}^{\S}\right)$ & 1.23 & $0.90-1.63$ & 0.172 & 0.74 & $0.58-0.97$ & $0.048^{*}$ \\
\hline Diabetes mellitus (yes vs. no) & 3.10 & $2.69-3.63$ & $<0.001 *$ & 1.92 & $1.53-2.35$ & $<0.001$ * \\
\hline Hypertension (yes vs. no) & 2.24 & $1.83-2.59$ & $<0.001 *$ & 1.12 & $0.89-1.49$ & 0.569 \\
\hline Hyperlipidemia (yes vs. no) & 1.93 & $1.58-2.35$ & $<0.001 *$ & 1.06 & $0.72-1.33$ & 0.611 \\
\hline Gout (yes vs. no) & 1.56 & $1.29-1.96$ & $<0.001 *$ & 0.94 & $0.60-1.35$ & 0.377 \\
\hline Congestive heart failure (yes vs. no) & 2.91 & $2.21-3.72$ & $<0.001 *$ & 1.30 & $0.99-1.66$ & 0.051 \\
\hline Coronary artery disease (yes vs. no) & 3.01 & $2.53-3.68$ & $<0.001 *$ & 1.59 & $1.28-1.92$ & $<0.001$ * \\
\hline $\begin{array}{c}\text { Cerebrovascular accident } \\
\text { (yes vs. no) }\end{array}$ & 2.97 & $2.31-3.51$ & $<0.001 *$ & 1.42 & $1.19-1.79$ & $<0.001$ * \\
\hline Peripheral arterial disease (yes vs. no) & 1.43 & $0.65-2.99$ & 0.358 & 0.90 & $0.40-1.99$ & 0.835 \\
\hline Chronic lung disease (yes vs. no) & 2.64 & $2.19-3.29$ & $<0.001 *$ & 1.42 & $1.14-1.75$ & $0.001 *$ \\
\hline Chronic liver disease (yes vs. no) & 1.95 & $1.57-2.53$ & $<0.001 *$ & 1.59 & $1.29-2.03$ & $<0.001$ * \\
\hline Malignancy (yes vs. no) & 1.83 & $1.35-2.49$ & $<0.001 *$ & 1.48 & $1.18-2.18$ & $0.004 *$ \\
\hline Retinopathy (yes vs. no) & 2.21 & $1.82-2.61$ & $<0.001 *$ & 1.20 & $0.92-1.45$ & 0.077 \\
\hline RCT (vs. non-RCT s) $^{2}$ & 0.59 & $0.44-0.79$ & $<0.001 *$ & 0.69 & $0.51-0.90$ & $0.001 *$ \\
\hline
\end{tabular}

${ }^{*} p<0.05 ; \S$ ref. HR = hazard ratio; $\mathrm{CI}=$ confidence interval; $\mathrm{HD}=$ Hemodialysis; $\mathrm{PD}=$ Peritoneal dialysis.

Table 4. Hazard ratios of risk of death among dialysis patients with RCT and without RCT.

\begin{tabular}{ccccc}
\hline All-Cause Death & Non-RCT & RCT & $\mathbf{9 5 \%}$ CI & $p$ \\
\hline Crude HR $^{\text {adjusted HR }}$ & 1 & 0.59 & $0.44-0.79$ & $<0.001^{*}$ \\
Adjusted HR $^{\text {b }}$ & 1 & 0.65 & $0.48-0.83$ & $<0.001^{*}$ \\
\hline
\end{tabular}

${ }^{*} p<0.05 . \mathrm{HR}=$ hazard ratio; $\mathrm{CI}=$ confidence interval; Both crude and adjusted HRs were calculated by Cox proportional hazard regressions. ${ }^{a}$ Adjustments were made for demographic variables (age, sex, monthly income, and dialysis style); ${ }^{\mathrm{b}}$ Adjustments were made for demographic variables and comorbidities (diabetes mellitus, hypertension, hyperlipidemia, gout, congestive heart failure, coronary artery disease, cerebrovascular accident, peripheral arterial disease, chronic lung disease, chronic liver disease, malignancy, and retinopathy).

\subsection{Causes of Death}

The causes of death are shown in Table 5. Infectious diseases had a significant role in mortality among dialysis patients with non-RCT ( $45.54 \%$ vs. $34.83 \% ; p=0.003)$.

Table 5. Cause of death.

\begin{tabular}{|c|c|c|c|c|c|}
\hline \multirow{3}{*}{ Variables } & \multirow{2}{*}{\multicolumn{2}{|c|}{$\begin{array}{l}\text { Non-RCT } \\
(\mathrm{n}=3430)\end{array}$}} & \multirow{2}{*}{\multicolumn{2}{|c|}{$\begin{array}{c}\text { RCT } \\
(n=600)\end{array}$}} & \multirow{3}{*}{$p$} \\
\hline & & & & & \\
\hline & $\mathbf{n}$ & $\%$ & $\mathbf{n}$ & $\%$ & \\
\hline \multicolumn{6}{|l|}{ Causes of death } \\
\hline Coronary artery disease & 599 & 17.46 & 83 & 13.83 & 0.410 \\
\hline Infectious disease & 1562 & 45.54 & 209 & 34.83 & 0.003 * \\
\hline Cerebrovascular disease & 387 & 11.28 & 97 & 16.17 & 0.189 \\
\hline Malignancy & 331 & 9.65 & 72 & 12.00 & 0.548 \\
\hline Other & 551 & 16.06 & 139 & 23.17 & 0.049 * \\
\hline
\end{tabular}




\section{Discussion}

Oral health and dental problems are easily neglected in patients undergoing maintenance dialysis. The strength of this study is the first population-based cohort design to investigate the potential effect of appropriate root canal therapy (RCT) on survival in these patients, including hemodialysis and peritoneal dialysis. The results of this study may provide a further prevention strategy for dialysis patients with dental problems. CKD is related to poor outcomes, including an excessive risk of kidney failure, cardiovascular disease, and mortality. These associations may result from the presence of biochemical abnormalities such as increased inflammatory factors, endothelial dysfunction, and enhanced coagulopathy. Accompanying the progressive decline in renal function, patients may have various oral symptoms, such as periodontal disease, decay, missing teeth, oral ulcers, gingival bleeding, halitosis, taste disturbances, uremic odors, periapical lesions, calculus formation, and pale mucosae [22]. The consequences of poor oral health may be more severe in CKD patients because of elderliness, frequent comorbidities such as diabetes, concurrent medications, and immunocompromised states. Kshirsagar et al. [23] reported that individuals with a glomerular filtration rate (GFR) of $<60 \mathrm{~mL} / \mathrm{min} / 1.73 \mathrm{~m}^{2}$ were more likely to have severe periodontal disease than healthy individuals (odds ratio, 2.00; 95\% confidence interval, 1.19-3.85).

The inflammatory response has impacted CKD as a risk factor for accelerating CKD progression. In fact, poor oral health is also regarded as a source of inflammation and a contributor to infectious diseases. Initially, patients usually present with gingivitis and periodontitis, which may cause systemic inflammation because of the formation of periodontal pockets colonized with Gram-negative anaerobic bacteria. An inflammatory cell infiltrate is recruited into the lesion and secretes proinflammatory mediators. In the Chronic Renal Insufficiency Cohort (CRIC) study, an inverse relationship between biomarkers of inflammation (interleukin-1 $\beta$, interleukin-1 receptor antagonist, interleukin-6, tumor necrosis factor- $\alpha, C$-reactive protein, and fibrinogen) and renal function was advocated [24]. Furthermore, malnutrition and uremic toxin accumulation in dialysis patients may induce immune dysfunction through defects in lymphocyte and monocyte function [8]. Chronic inflammation is thought to contribute to several complications, including arteriosclerosis, atherosclerosis, osteoporosis, frailty, diabetes, malignancy, and so on. Otherwise, the inflammatory and oxidative stress responses may worsen endothelial dysfunction in ESRD patients, accelerate coronary plaque formation, and increase cardiovascular risks $[6,25]$. Concerning the comorbidities of cardiovascular disease and diabetes mellitus, there was a significant difference ( $p$ value $<0.05$ ) in our study, which might have resulted from the excessive inflammatory status in patients with poor dental health who did not receive RCT for improvement.

Similar to periodontal inflammation, microbial infection in the root canal system and the periradicular area is prevalent in patients with CKD and ESRD [26]. Persistent root canal infections, such as apical periodontitis, may contribute to infected microorganisms and inflammatory mediators invading the dentinal tubules, accessory canals, and brokendown periapical tissues. Common systemic infectious diseases originating from endodontic infection include bacteremia, endocarditis, aspiration pneumonia, and membranous candidiasis. Chronic bacterial infection is also an important risk factor for atherosclerotic complications and thromboembolic events, which increase the incidence of coronary heart disease [27]. Infection, bacteremia, and sepsis are crucial sources of morbidity and mortality in ESRD patients receiving chronic renal replacement therapy. A previous study disclosed that mortality caused by infection in individuals with both a decreased estimated glomerular filtration rate and an elevated albumin to creatinine ratio was approximately 100- to 300-fold higher for chronic dialysis patients than for the general public [28]. A more advanced proportion of hospital-acquired infections is also noted in dialysis patients due to long-term dialysis-related exposure. When dialysis patients suffer from concomitant dental infection, a complete cycle of antibiotic treatment should be administered. Penicillin, cephalosporins, clindamycin, and their derivatives are safer choices for these patients [29]. 
In contrast to many studies, in our study, infectious disease was the leading cause of death. We found that more people died from infectious diseases in the non-RCT group (1562 in 3430 patients, $45.54 \%$ ) than in the RCT group (209 in 600 patients, $34.83 \%$ ). Furthermore, a tendency for dialysis patients without RCT having a higher all-cause mortality rate (34.93\% in the non-RCT group and $22.79 \%$ in the RCT group) was also observed.

Lower socioeconomic status (SES) is a risk factor for CKD and progression to endstage renal disease [30]. Aside from the cross interaction between dental problems and the decline in renal function mentioned above, oral health is usually a lower priority for low SES families, especially those who are struggling with economic hardships and other medical needs. Toothbrushes and toothpaste are the most commonly used oral hygiene products and represent the most effective way to clean teeth. Previous studies have demonstrated that patients with upper SES tend to have sufficient cleaning aids for personal oral hygiene, whereas this is lacking among patients with a lower SES [31-33]. The potential benefit of dental health is reflected in survival, cardiovascular events, and quality of life, which might be significant in adults with CKD compared with other settings due to the more severe spectrum of oral disease and infrequent use of dental care practices [17]. In Taiwan, root canal treatment is a high-cost technique and is only partially covered by health insurance. We found that patients with a low SES were more prone to having a higher mortality rate in our study $(23.42 \%$ in the no income group; $15.21 \%$ in the NT\$1-15,840 group; $50.25 \%$ in the NT\$15,841-25,000 group; and $11.12 \%$ in the $\geq N T \$ 25,001$ group), which infers that oral health might be more easily neglected in patients with a low SES than in those with a medium or high SES. Even if they discover these dental problems, they would most likely choose low-cost procedures, such as tooth extraction, instead of high-cost techniques, such as RCT. Tooth loss may increase infectious agents in oral health, accelerate atherosclerosis progression, disturb plaque stability, and cause excessive malnutrition, and it may be considered a potential risk marker for all-cause mortality [34]. A systematic review by Koka and Gupta also reported that a reduced tooth count was associated with higher mortality [35]. However, a recent retrospective case-control study recommended that radical dental interventions to chronic oral infections could be postponed until post-hematopoietic stem cell transplantation [36].

Several previous studies have advocated that poor oral health may be an important risk factor for all-cause mortality in dialysis patients. Although patients in the RCT group were slightly younger $(54.93 \pm 13.84)$ than those in the non-RCT group $(57.02 \pm 14.75)$, there was still a significant difference in survival probability between these two groups. Through the multivariate regression analysis for the risk of death, the history of diabetes mellitus, coronary artery disease, cerebrovascular accident, chronic lung disease, chronic liver disease, and malignancy all have greater hazard ratios than that of the difference of age. In the other hands, receiving RCT plays a protective role in this analysis. At the same time, for those who without RCT, infectious disease is the leading cause of mortality, whereas these comorbidities mentioned above only have a minor effect. To the best of our knowledge, this is the first retrospective cohort study to explore whether the mortality rate decreases in dialysis patients receiving RCT.

\section{Limitations}

The strengths of this study are its population-based research, use of well-established cohort data with a large sample size, and extended follow-up period to investigate the impact of RCT on survival among dialysis patients. However, this study has several limitations. First, claims data were identified from the NHI database under the principal payment code for the dental service, and complete dental examinations were not performed during face-to-face interviews; however, the decision criteria and ICD-9 coding system for subjects of dental intervention, such as dental filling, periodontal therapy, and RCT, are judged by clinicians. Second, our collected data may still have minor inaccuracies. The accuracy of these data from the NHI database is improved by a cross-checking system with full review by specialists. Thus, these inaccuracies would have a minimal impact on the 
results. Third, some clinical and laboratory data, such as blood pressure, glycemic control, $\mathrm{Kt} / \mathrm{V}$, body mass index, albumin, blood urea nitrogen, creatinine, and inflammatory status, could not be obtained from our database. Meanwhile, the relevance of superior survival probability to receiving RCT and a meaningful impact of infectious disease leading to mortality among the dialysis patients without optimal RCT were revealed in our study. Further prospective studies were needed to identify the clinical or laboratory markers for prognosis or to analyze the infectious episode occurring secondary to dental problems. Regardless of these limitations, our study still has several strengths, including the important advantage of relying on real-world population-based data, a relatively substantial sample size, and the analysis of risk factors and survival results of dialysis patients in Taiwan.

\section{Conclusions}

Our study contributes to filling the knowledge gap, showing relatively better survival in the RCT group than in the non-RCT group among dialysis patients, including hemodialysis and peritoneal dialysis patients. This suggests that we should also never neglect the importance of oral health and endodontic disease in these high-risk patients. Appropriate interventions for dental problems may offer advantages. However, a large and prospective study is warranted to clarify the connection between CKD stage and DENT utilization in CKD subjects.

Author Contributions: Conceptualization, R.-Y.H., W.-C.C. and P.-J.H.; data collection, R.-Y.H., J.S.C., Y.-H.K. and P.-J.H.; formal analysis, C.-C.C., C.-H.C., W.-C.C., Y.-H.K. and P.-J.H.; methodology, W.-C.C. and P.-J.H.; writing—original draft, C.-C.C. and Y.-C.C.; writing—review and editing, C.C.C., Y.-C.C., Y.-H.K. and P.-J.H. All authors have read and agreed to the published version of the manuscript.

Funding: This study was supported by grants from the Research Fund of the Taoyuan Armed Forces General Hospital (TYAFGH-E-109052 and TYAFGH-D-110032), and Tri-Service Forces General Hospital (TSGH-B-110012).

Institutional Review Board Statement: The study was conducted according to the guidelines of the Declaration of Helsinki, and approved by the Institutional Review Board of Tri-Service General Hospital, National Defense Medical Center (Approval No: TSGHIRB-B-109-37).

Informed Consent Statement: Not applicable.

Data Availability Statement: Restrictions apply to the availability of these data. Data was obtained from National Health Insurance database and are available from the authors with the permission of National Health Insurance Administration of Taiwan.

Conflicts of Interest: The authors declare that they have no conflict of interest.

\section{References}

1. 2019 USRDS Annual Data Report. Volume 2: ESRD in the United States. Chapter 11: International Comparisons. Available online: https://www.usrds.org/annual-data-report/previous-adrs / (accessed on 31 December 2020).

2. Tsai, S.Y.; Tseng, H.F.; Tan, H.F.; Chien, Y.S.; Chang, C.C. End-stage renal disease in Taiwan: A case-control study. J. Epidemiol. 2009, 19, 169-176. [CrossRef] [PubMed]

3. Bello, A.K.; Alrukhaimi, M.; Ashuntantang, G.E.; Basnet, S.; Rotter, R.C.; Douthat, W.G.; Kazancioglu, R.; Köttgen, A.; Nangaku, M.; Powe, N.R.; et al. Complications of chronic kidney disease: Current state, knowledge gaps, and strategy for action. Kidney Int. Suppl. 2017, 7, 122-129. [CrossRef] [PubMed]

4. Vogelzang, J.L.; van Stralen, K.J.; Noordzij, M.; Diez, J.A.; Carrero, J.J.; Couchoud, C.; Dekker, F.W.; Finne, P.; Fouque, D.; Heaf, J.G.; et al. Mortality from infections and malignancies in patients treated with renal replacement therapy: Data from the ERA-EDTA registry. Nephrol. Dial. Transpl. 2015, 30, 1028-1037. [CrossRef] [PubMed]

5. Al Wakeel, J.S.; Mitwalli, A.H.; Al Mohaya, S.; Abu-Aisha, H.; Tarif, N.; Malik, G.H.; Hammad, D. Morbidity and mortality in ESRD patients on dialysis. Saudi J. Kidney Dis. Transpl. 2002, 13, 473-477.

6. Aoki, J.; Ikari, Y. Cardiovascular disease in patients with end-stage renal disease on hemodialysis. Ann. Vasc. Dis. 2017, 10, 327-337. [CrossRef]

7. Katarzynska-Konwa, M.; Obersztyn, I.; Trzcionka, A.; Mocny-Pachonska, K.; Mosler, B.; Tanasiewicz, M. Oral Status in Pregnant Women from Post-Industrial Areas of Upper Silesia in Reference to Occurrence of: Preterm Labors, Low Birth Weight and Type of Labor. Healthcare 2020, 8, 528. [CrossRef] 
8. Ruospo, M.; Palmer, S.C.; Craig, J.C.; Gentile, G.; Johnson, D.W.; Ford, P.J.; Tonelli, M.; Petruzzi, M.; De Benedittis, M.; Strippoli, G.F. Prevalence and severity of oral disease in adults with chronic kidney disease: A systematic review of observational studies. Nephrol. Dial. Transpl. 2014, 29, 364-375. [CrossRef]

9. Akar, H.; Akar, G.C.; Carrero, J.J.; Stenvinkel, P.; Lindholm, B. Systemic consequences of poor oral health in chronic kidney disease patients. Clin. J. Am. Soc. Nephrol. 2011, 6, 218-226. [CrossRef]

10. Borawski, J.; Wilczyńska-Borawska, M.; Stokowska, W.; Myśliwiec, M. The periodontal status of pre-dialysis chronic kidney disease and maintenance dialysis patients. Nephrol. Dial. Transpl. 2007, 22, 457-464. [CrossRef]

11. Thorman, R.; Neovius, M.; Hylander, B. Clinical findings in oral health during progression of chronic kidney disease to end-stage renal disease in a Swedish population. Scand. J. Urol. Nephrol. 2009, 43, 154-159. [CrossRef]

12. Palmer, S.C.; Ruospo, M.; Wong, G.; Craig, J.C.; Petruzzi, M.; De Benedittis, M.; Ford, P.; Johnson, D.W.; Tonelli, M.; Natale, P.; et al. Dental health and mortality in people with end-stage kidney disease treated with hemodialysis: A multinational cohort study. Am. J. Kidney Dis. 2015, 66, 666-676. [CrossRef] [PubMed]

13. Chao, H.L.; Lyu, J. A study of dental services in Taiwan before and after global budgeting. Int. J. Electron. Bus. Manag. 2010, 8 , 139-151.

14. Trzcionka, A.; Twardawa, H.; Mocny-Pachońska, K.; Tanasiewicz, M. Oral cavity status of long-term hemodialized patients vs. their socio-economic status. Med. Pr. 2020, 71, 279-288. [CrossRef] [PubMed]

15. Scannapieco, F.A.; Cantos, A. Oral inflammation and infection, and chronic medical diseases: Implications for the elderly. Periodontology 2000 2016, 72, 153-175. [CrossRef] [PubMed]

16. López-Pintor, R.M.; López-Pintor, L.; Casañas, E.; de Arriba, L.; Hernández, G. Risk factors associated with xerostomia in haemodialysis patients. Med. Oral Patol. Oral Cir. Bucal. 2017, 22, e185-e192. [CrossRef]

17. Cheng, C.L.; Kao, Y.H.; Lin, S.J.; Lee, C.H.; Lai, M.L. Validation of the National Health Insurance Research Database with ischemic stroke cases in Taiwan. Pharmacoepidemiol. Drug Saf. 2011, 20, 236-242. [CrossRef]

18. Hsieh, C.Y.; Su, C.C.; Shao, S.C.; Sung, S.F.; Lin, S.J.; Kao Yang, Y.H.; Lai, E.C. Taiwan's National Health Insurance Research Database: Past and future. Clin. Epidemiol. 2019, 11, 349-358. [CrossRef]

19. Tsai, Y.D.; Chien, W.C.; Tsai, S.H.; Chung, C.H.; Chu, S.J.; Chen, S.J.; Liao, W.I.; Yang, C.J.; Liao, M.T.; Wang, J.C. Increased risk of aortic aneurysm and dissection in patients with Sjögren's syndrome: A nationwide population-based cohort study in Taiwan. BMJ Open 2018, 8, e022326. [CrossRef]

20. Shih, C.P.; Lin, H.C.; Chung, C.H.; Hsiao, P.J.; Wang, C.H.; Lee, J.C.; Chien, W.C. Increased risk of tinnitus in patients with chronic kidney disease: A nationwide, population-based cohort study. PLoS ONE 2017, 12, e0183192. [CrossRef]

21. Hsiao, P.J.; Wu, K.L.; Chiu, S.H.; Chan, J.S.; Lin, Y.F.; Wu, C.Z.; Wu, C.C.; Kao, S.; Fang, T.C.; Lin, S.H.; et al. Impact of the use of anti-diabetic drugs on survival of diabetic dialysis patients: A 5-year retrospective cohort study in Taiwan. Clin. Exp. Nephrol. 2017, 21, 694-704. [CrossRef]

22. Honarmand, M.; Farhad-Mollashahi, L.; Nakhaee, A.; Sargolzaie, F. Oral manifestation and salivary changes in renal patients undergoing hemodialysis. J. Clin. Exp. Dent. 2017, 9, e207-e210. [CrossRef] [PubMed]

23. Kshirsagar, A.V.; Craig, R.G.; Beck, J.D.; Moss, K.; Offenbacher, S.; Kotanko, P.; Yoshino, M.; Levin, N.W.; Yip, J.K.; Almas, K.; et al. Severe periodontitis is associated with low serum albumin among patients on maintenance hemodialysis therapy. Clin. J. Am. Soc. Nephrol. 2007, 2, 239-244. [CrossRef] [PubMed]

24. Amdur, R.L.; Feldman, H.I.; Gupta, J.; Yang, W.; Kanetsky, P.; Shlipak, M.; Rahman, M.; Lash, J.P.; Townsend, R.R.; Ojo, A.; et al. Inflammation and progression of CKD: The CRIC study. Clin. J. Am. Soc. Nephrol. 2016, 11, 1546-1556. [CrossRef] [PubMed]

25. Cobo, G.; Lindholm, B.; Stenvinkel, P. Chronic inflammation in end-stage renal disease and dialysis. Nephrol. Dial. Transplant. 2018, 33, iii35-iii40. [CrossRef]

26. Ariyamuthu, V.K.; Nolph, K.D.; Ringdahl, B.E. Periodontal disease in chronic kidney disease and end-stage renal disease patients: A review. Cardiorenal. Med. 2013, 3, 71-78. [CrossRef]

27. Pussinen, P.J.; Tuomisto, K.; Jousilahti, P.; Havulinna, A.S.; Sundvall, J.; Salomaa, V. Endotoxemia, immune response to periodontal pathogens, and systemic inflammation associate with incident cardiovascular disease events. Arterioscler. Thromb. Vasc. Biol. 2007, 27, 1433-1439. [CrossRef]

28. Wang, H.E.; Gamboa, C.; Warnock, D.G.; Muntner, P. Chronic kidney disease and risk of death from infection. Am. J. Nephrol. 2011, 34, 330-336. [CrossRef]

29. Costantinides, F.; Castronovo, G.; Vettori, E.; Frattini, C.; Artero, M.L.; Bevilacqua, L.; Berton, F.; Nicolin, V.; Di Lenarda, R. Dental care for patients with end-stage renal disease and undergoing hemodialysis. Int. J. Dent. 2018, 2018, 9610892. [CrossRef]

30. Huang, R.Y.; Lin, Y.F.; Kao, S.Y.; Shieh, Y.S.; Chen, J.S. A retrospective case-control analysis of the outpatient expenditures for western medicine and dental treatment modalities in CKD patients in Taiwan. PLoS ONE 2014, 9, e88418. [CrossRef]

31. Assari, S. Socioeconomic status and self-rated oral health; diminished return among hispanic whites. Dent. J. $2018,6,11$. [CrossRef]

32. Park, J.B.; Han, K.; Park, Y.G.; Ko, Y. Association between socioeconomic status and oral health behaviors: The 2008-2010 Korea national health and nutrition examination survey. Exp. Ther. Med. 2016, 12, 2657-2664. [CrossRef] [PubMed]

33. Oberoi, S.S.; Sharma, G.; Oberoi, A. A cross-sectional survey to assess the effect of socioeconomic status on the oral hygiene habits. J. Indian Soc. Periodontol. 2016, 20, 531-542. [CrossRef] [PubMed] 
34. Peng, J.; Song, J.; Han, J.; Chen, Z.; Yin, X.; Zhu, J.; Song, J. The relationship between tooth loss and mortality from all causes, cardiovascular diseases, and coronary heart disease in the general population: Systematic review and dose-response meta-analysis of prospective cohort studies. Biosci. Rep. 2019, 39, BSR20181773. [CrossRef] [PubMed]

35. Koka, S.; Gupta, A. Association between missing tooth count and mortality: A systematic review. J. Prosthodont. Res. 2018, 62, 134-151. [CrossRef] [PubMed]

36. Mauramo, M.; Grolimund, P.; Egli, A.; Passweg, J.; Halter, J.; Waltimo, T. Dissociations of oral foci of infections with infectious complications and survival after haematopoietic stem cell transplantation. PLoS ONE 2019, 14, e0225099. [CrossRef] [PubMed] 